\title{
2-lodoxybenzoic Acid: An Oxidant for Functional Group Transformations: (A-Review)
}

\author{
VIPIN A. NAIR \\ Department of chemistry, REVA University, Yelahanka, Bangalore 560064, India. \\ *Corresponding author E-mail: vn74nr@gmail.com \\ http://dx.doi.org/10.13005/ojc/360501
}

(Received: August 28, 2020; Accepted: September 29, 2020)

\begin{abstract}
A major application of 2-lodoxybenzoic acid (IBX) is the oxidation of alcohols to carbonyl compounds, at room temperature. IBX is insoluble in almost all solvents, except DMSO. IBX tolerates amine functionality and is therefore used for the oxidation of amino alcohols to amino carbonyl compounds. IBX oxidizes 1,2-glycols without the cleavage of the glycol carbon-carbon bond. Allylic and benzylic positions are also susceptible to oxidation by IBX. Synthesis of $\alpha, \beta$-unsaturated carbonyl compounds from carbonyl compounds can be accomplished by using IBX as oxidant. Silyl enol ethers undergo oxidation upon exposure to IBX and 4-methoxypyridine $\mathrm{N}$-oxide. Water-soluble derivatives of IBX, and polymer-based IBX, with additional advantages, have also been developed. IBX mediated transformations facilitate the construction of diverse heterocyclic systems.
\end{abstract}

Keywords: 2-Iodoxybenzoic acid, Oxidation, Alcohols, Carbonyl compounds, Single electron transfer.

\section{INTRODUCTION}

2-lodoxybenzoic acid (IBX), a hypervalent iodine(V) reagent (Fig. 1) finds numerous applications as an oxidant. It is effective in carrying out oxidation of alcohols, benzylic and allylic sites, and carbon centres adjacent to carbonyl functionalities. Inferences drawn from studies indicate that some of these reactions proceed by single electron transfer (SET) mechanism. Electron transfer from the substrate to IBX forms a radical cation, which is converted to product. Detailed investigations on multifunctional substrates would allow to decipher the chemo- and regioselectivity of the reactions. The reagent has the potential to be one of the highly useful oxidants in organic synthesis.<smiles>O=C1O[Te](=O)(O)c2ccccc21</smiles><smiles>CC(=O)O[Te]1(OC(C)=O)OC(=O)c2ccccc21</smiles>

2-lodoxybenzoic acid (IBX) Dess-Martin Periodinane (DMP)

Fig. 1. Hypervalent lodine reagents

2-lodoxybenzoic acid (IBX) is known for several decades, but its utility was limited by insolubility in most organic solvents, except DMSO. IBX is easily prepared from 2-iodobenzoic acid by an oxidation reaction. Oxone $\left(2 \mathrm{KHSO}_{5}-\mathrm{KHSO}_{4}-\mathrm{K}_{2} \mathrm{SO}_{4}\right)$ is widely employed as an oxidant in the preparation of IBX. ${ }^{\top}$ The oxidation is performed at $70^{\circ} \mathrm{C}$ in water

This is an Open Access article licensed under a Creative Commons license: Attribution 4.0 International (CC- BY). Published by Oriental Scientific Publishing Company @ 2018

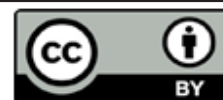


(Fig. 2). IBX is crystallized out of the reaction mixture in high yields and good purity, by cooling. Use of excess of oxone reduces the reaction time. The procedure is environment friendly, with the sulfate salts as the only by products.<smiles>O=C(O)c1ccccc1I</smiles><smiles>O=C1OI(=O)(O)c2ccccc21</smiles>

IBX

Fig. 2. Preparation of IBX using Oxone

IBX has been used to convert alcohols and 1,2-diols to carbonyl compounds (Scheme 1). The transformation occurs without over-oxidation (Table 1, Entries 1,2) to carboxylic acids. ${ }^{2}$ IBX does not require an inert atmosphere for the reaction.

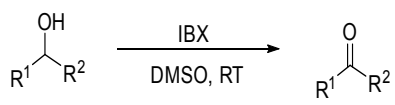

$\underset{D M S O, R T}{\text { IBX }}$

Scheme 1. Oxidation of alcohols and 1,2-diols

Alcohols can be selectively oxidised in the presence of amines (Table 1, Entry 3). Thus IBX converts amino alcohols to amino carbonyl compounds (Scheme 2). Amines are usually protonated in situ with an acid (TFA), during the reaction. ${ }^{3}$<smiles>[R20]C(C)C(O)C(C)C(=O)c1ccccc1</smiles>

Scheme 2. Oxidation of amino alcohols

Carboxylic acids and esters remain intact in presence of IBX, while phenols are unstable (Table 1, Entry 4). At room temperature, phenols undergo double oxidation (Scheme 3) to afford o-quinones. ${ }^{4}$ However, phenols with electron withdrawing groups are not oxidised.<smiles>[X]c1ccc(I)cc1I</smiles><smiles>C[Mg]C(C)(C)Br</smiles>

$X, Y$ - Electron donating groups<smiles>[X]C1=CC(=O)C([Y])C=C1</smiles>
Scheme 3. Oxidation of phenols

1,4-Diols are oxidised to $\gamma$-lactols (Table 1 , Entry 5) in good yields. ${ }^{5}$ No over-oxidation to lactones was observed. For instance, the diol prepared by hydroboration of (1S)-isopulegol afforded a diastereomeric mixture of lactols (Scheme 4).<smiles>C[C@H]1CC[C@@H](O)[C@H](C)C1</smiles>

Scheme 4. Oxidation of 1,4-diols

Table 1: IBX mediated functional group transformations

Entry




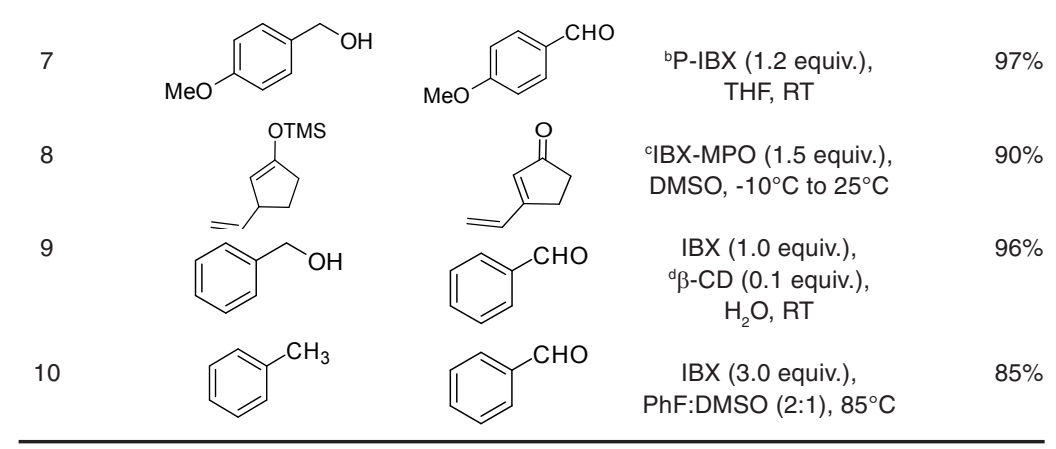

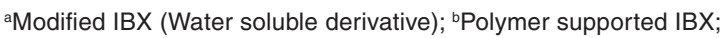

IBX-Methoxy Pyridine N-oxide; ${ }^{d} \beta$-Cyclodextrin

A water-soluble derivative of IBX was developed for oxidizing alcohols. The synthesis was achieved by the conversion of 3-nitrophthalic acid to 3-iodophthalic acid (Fig. 3) and subsequent oxidation using $\mathrm{KBrO}_{3} \cdot{ }^{6}$ This derivative of IBX oxidises allylic and benzylic alcohols in water (Scheme 5). Over-oxidation products were not observed (Table 1, Entry 6).

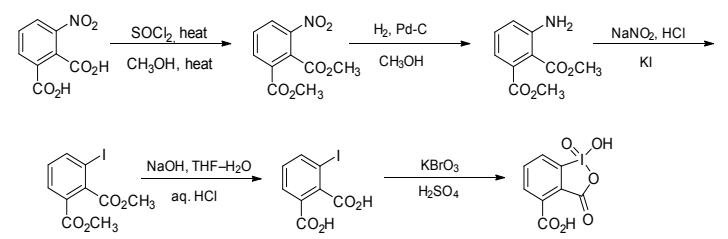

Fig. 3. Preparation of water-soluble derivative of IBX

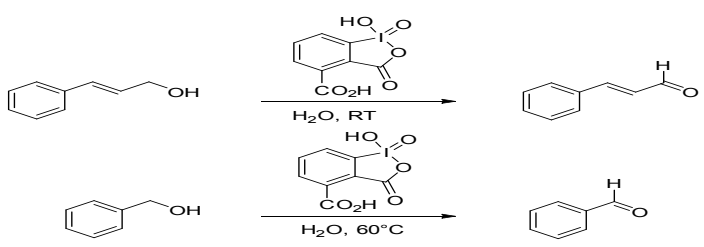

Scheme 5. Oxidation of allylic and benzylic alcohols

2-Amino-5-hydroxybenzoic acid was transformed to the tert-butyl ester of 2-iodo-5hydroxy benzoic acid (Fig. 4). The phenolic hydroxy group was subsequently coupled to aminopropylsilica gel with acetyl group as the linker. Cleavage of the tert-butyl ester and oxidation with oxone afforded the polymer-supported IBX reagent. ${ }^{7}$ Primary and secondary alcohols were oxidized by this reagent, in THF medium (Table 1, Entry 7). This reagent offers the advantages of polymer-support and the oxidant. The reduced reagent was separated by filtration, and regenerated by oxidation.

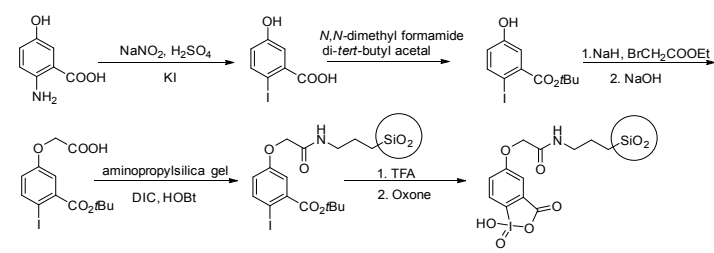

Fig. 4. Preparation of polymer supported IBX
A complex of IBX and 4-methoxypyridine $\mathrm{N}$-oxide (MPO) (Scheme 6) converts carbonyl compounds and trimethyl silyl enol ethers into corresponding $\alpha, \beta$-unsaturated carbonyl compounds. ${ }^{8}$ Reactive groups such as amines, sulfides and mesylates were unaffected. The enolate formed by the conjugate addition of a cuprate reagent (RMgX, $\mathrm{CuBr} . \mathrm{SMe}_{2}$ ) to an enone was trapped as the silyl enol ether. Subsequent oxidation of the silyl enol ether regenerated a $\beta$-substituted enone (Table 1, Entry 8).

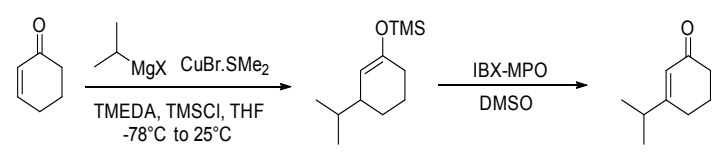

Scheme 6. Conversion of silyl enol ethers to enones

The dehydrogenation reactions of carbonyl compounds proceed through enolization facilitated by IBX. This is followed by a single electron transfer to IBX. The resulting radical cation affords $\alpha, \beta$-unsaturated carbonyl compound (Fig. 5 ). It is assumed that the silyl enol ethers also undergo a similar oxidation with IBX.

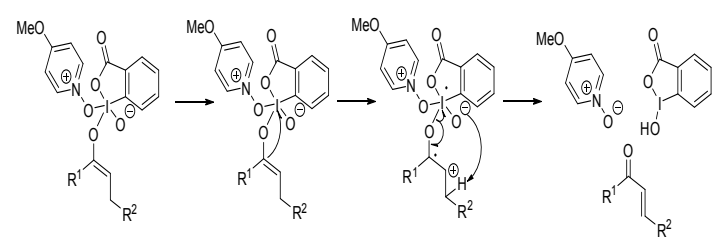

Fig. 5. Formation of $\alpha, \beta$-unsaturated carbonyl compounds

$\beta$-Cyclodextrin catalyses the oxidation of alcohols and diols, with IBX. Water-acetone mixture was employed as the solvent. ${ }^{9}$ Cyclodextrin exerts catalytic effect through non-covalent interactions. Aryl carbinols (Table 1, Entry 9) gave better yields than the aliphatic alcohols. Selectivity was observed with vicinal diols, oxidizing only the secondary hydroxy group $\alpha$ to the benzene ring (Scheme 7). 
<smiles>OCC(O)c1ccccc1</smiles>

$$
\underset{\text { D-Cyclodextrin }}{\stackrel{\mathrm{IBX}}{\text { Water-Acetone, RT }}}
$$<smiles>O=C(CO)c1ccccc1</smiles>

Scheme 7. $\beta$-cyclodextrin catalysed oxidation of benzyl alcohol

Oxidation of benzylic positions (Table 1 , Entry 10) occurs efficiently with IBX in DMSO at 80$90^{\circ} \mathrm{C} .{ }^{10}$ Over-oxidation products were not observed even in the case of electron-rich substrates. Tetrahydronaphthalenes yielded the corresponding ketones (Scheme 8). The selective oxidation of tetrahydronaphthalenes to mono-carbonyl systems is achieved by retardation of the reaction using electron withdrawing substituents.<smiles>COc1cccc2c1CCCC2=O</smiles>

Scheme 8. Oxidation of tetrahydronaphthalene

IBX behaves as a heterogeneous oxidant in insoluble solvents. ${ }^{11}$ However at elevated temperatures, IBX becomes sufficiently soluble in solvents such as EtOAc or DCE to permit oxidation of alcohols (Table 2, Entry 1) to the corresponding aldehydes and ketones (Scheme 9). It was observed that with excess oxidant, the reaction rate increases.

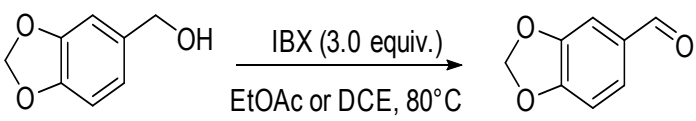

Scheme 9. Oxidation using IBX in insoluble solvents

Oxidation of benzyl alcohol to benzaldehyde was achieved using IBX in $\mathrm{DCM}-\mathrm{H}_{2} \mathrm{O}(1: 1)$ medium (Scheme 10) with 0.5 equiv. of $n-\mathrm{Bu}_{4} \mathrm{NBr}$ (TBAB). ${ }^{12}$ While the oxidation of alcohols was effective with 1.5 equiv. of IBX, it was found that for diols 3.0 equiv. of IBX was required (Table 2, Entry 2). Very small amounts of dicarbonyls or lactones were observed in the oxidation of diols. The transformation was also chemoselective with respect to the nature of the hydroxy groups. When present in the same molecule, the secondary hydroxy group was converted to ketone whereas the primary hydroxy group remained intact.

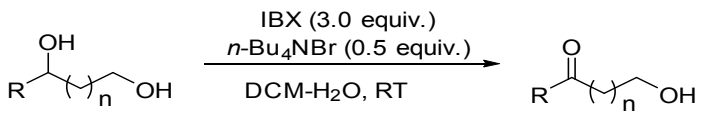

Scheme 10. TBAB assisted oxidation of alcohols and diols

In the presence of oxone (Scheme 11), the oxidation of alcohols could be carried out with catalytic amount of IBX, in acetonitrile-water (2:1) medium. ${ }^{13} 2$-lodosobenzoic acid (IBA) formed during the reaction was re-oxidised in situ (Table 2, Entry 3). This observation prompted the use of IBA as a catalytic oxidant in place of IBX.

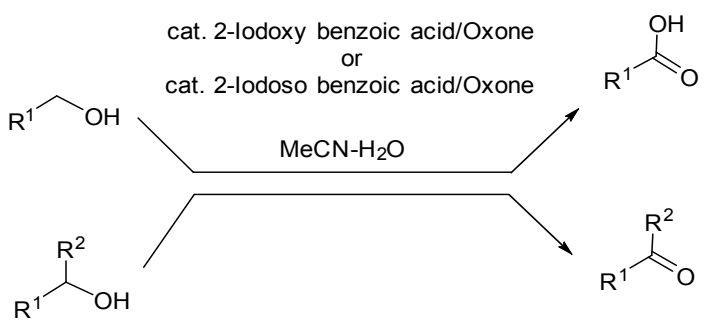

Scheme 11. Oxone as a co-oxidant in IBX or IBA mediated oxidations

IBX oxidation of aldol substrates (Scheme 12) yielded diketones. ${ }^{14}$ Substitution at the $\alpha$-position of the hydroxyketone was tolerated. The reaction did not discriminate between the syn and anti aldol diastereomers. The mild nature of the reaction condition was demonstrated in the reactions of $\alpha$-iodosubstrates, which gave the relatively stable $\alpha$-iodo- $\beta$-diketones (Table 2, Entry 4). Surprisingly, the oxidation of $\beta$-hydroxyketones failed with DMP.

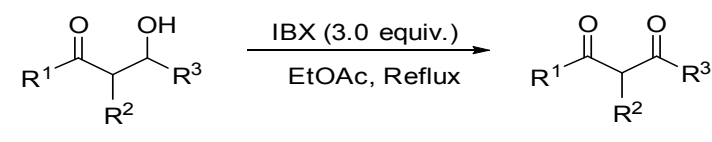

Scheme 12. Oxidation of aldol substrates

IBX was effective in converting carbonyl functionalities to $\alpha, \beta$-unsaturated carbonyl compounds (Scheme 13). Benzylic centers were oxidized to form conjugated aromatic carbonyl compounds. On varying the stoichiometry and temperature, IBX dehydrogenates cyclooctanol to either cyclooctenone or cyclooctadienone (Table 2, Entry 5).15 The cyclooctadienone formation paved the way for the total synthesis of a tropinone analog.

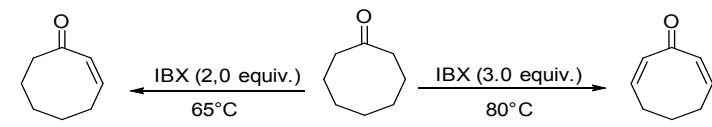

Scheme 13. Conversion of carbonyl compounds to $\alpha, \beta$-unsaturated carbonyl compounds

Oxidation of electron rich sites, such as the benzylic position occurs through single electron transfer (Fig. 6). Subsequent loss of a proton generates the benzyl radical. This intermediate undergoes another oxidation to give the benzyl carbocation which is transformed to alcohol, and further oxidised to the carbonyl functionality.

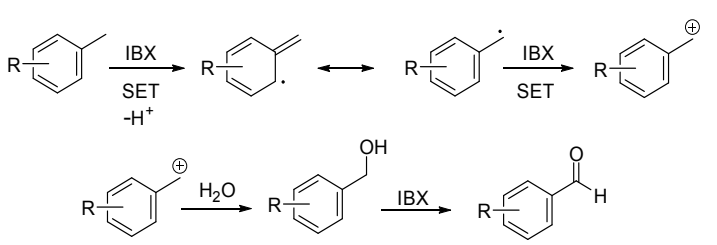

Fig. 6. Oxidation of benzylic centres by SET mechanism 
Table 2: IBX mediated oxidation reactions

(IB)

In the presence of molecular iodine, IBX generates hypoiodous acid (HOI). Hypoiodous acid reacts with olefins and $\alpha, \beta$-unsaturated ketones to afford iodohydrins (Scheme 14) with anti stereochemistry (Table 2, Entry 6). ${ }^{16}$ Epoxides can be obtained by a one-pot reaction through sequential iodohydroxylation and dehydroiodocyclization. An acidified solution of $\mathrm{HOI}$ produces iodonium ions (Fig. 7), which can iodinate aromatic compounds.

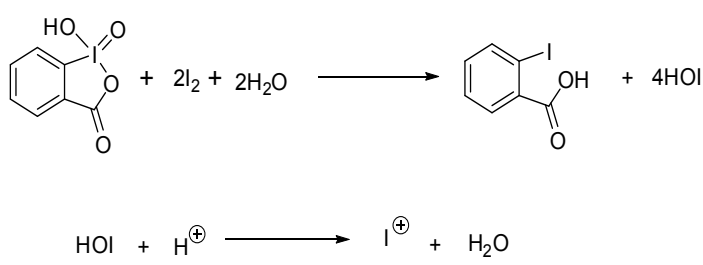

Fig. 7. Formation of hypoiodous acid and iodonium ions

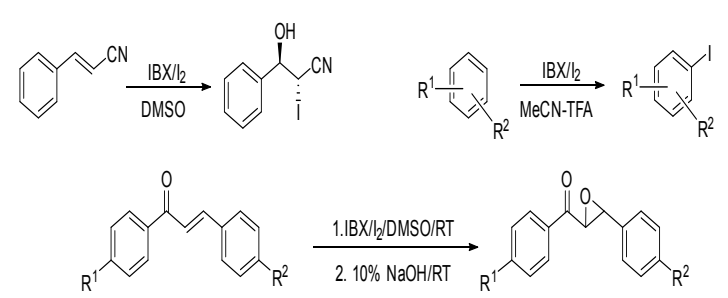

Scheme 14. IBX-lodine mediated reactions of unsaturated systems

An equimolar ratio of IBX and tetraethylammonium bromide (TEAB) in acetonitrile converts $\mathrm{N}, \mathrm{N}$-disubstituted glycylamides (Table 2, Entry 7) to cyanamides, ${ }^{17}$ by one carbon dehomologation (Scheme 15). In the case of 2-(4-benzylpiperidin1 -yl)acetamide, the benzylic position remains unaffected during the oxidation, illustrating the chemoselectivity. 


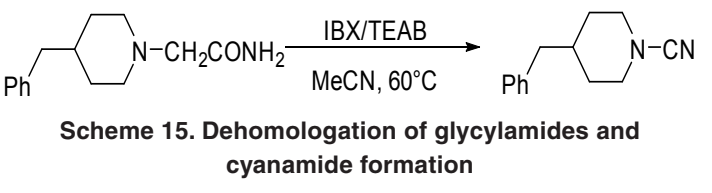

Thioureas are rapidly transformed to carbodiimide ${ }^{18}$ using IBX and triethylamine in DCM (Scheme 16). Sulfur is precipitated during the reaction. A molar ratio of 1:1:2 for substrate/ $\mathrm{IBX} /$ triethylamine was required for the reaction to complete (Table 2, Entry 8).<smiles>CC(C)(C)N1CCN(c2ccccc2)CC1</smiles>

Scheme 16. Formation of carbodiimide from thiourea

Olefins were converted to $\alpha$-bromoketones (Scheme 17) by employing IBX in combination with tetraethylammonium bromide (Table 2, Entry 9). An equimolar ratio of IBX/TEAB in anhydrous DCM, yielded $\alpha$-bromocyclohexanone from cyclohexene. ${ }^{19}$ Regioselectivity was observed with terminal olefins which gave only $\alpha$-bromo ketones, but not the isomeric $\alpha$-bromoaldehydes.

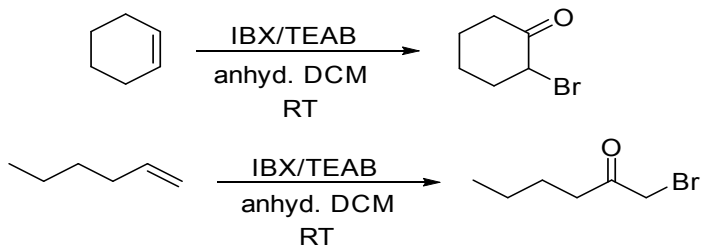

Scheme 17. TEAB mediated formation of $\alpha$-bromoketones

IBX effects $\alpha$-hydroxylation of $\alpha$-alkynyl carbonyl compounds (Scheme 18). Thus hydroxylation of 2-(2-phenylethynyl) cyclohexanone to 2-hydroxy2-(2-phenylethynyl) cyclohexanone (Table 2, Entry 10) was achieved using IBX in DMSO at room temperature. ${ }^{20}$ This mildly acidic method serves as an alternative to other $\alpha$-hydroxylation protocols.

$\underbrace{R}_{R^{2}} \frac{\text { IBX(1.5 equiv.) }}{\text { DMSO, } R T} R_{R^{2}}^{R} \underbrace{O H}_{R^{1}}$

Scheme 18. $\alpha$-Hydroxylation of $\alpha$-alkynyl carbonyl compounds

Conversion of oximes to carbonyl compounds (Scheme 19) was achieved by IBX in presence of $\alpha$-cyclodextrin. ${ }^{21}$ The reaction was performed in aqueous medium at room temperature (Table 3, Entry 1). Oximes having an aromatic moiety gave better yields. The reaction tolerates halo, nitro, hydroxy and methoxy groups. The deoximation reaction does not occur in the absence of $\alpha$-cyclodextrin.

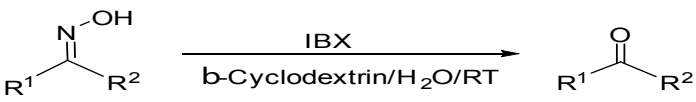
Scheme 19. Conversion of oximes to carbonyl compounds

Hydrolysis of thioacetals/thioketals (Table 3 , Entry 2) to the corresponding carbonyl compounds (Scheme 20) was attained with IBX in presence of $\alpha$-cyclodextrin at room temperature..$^{22}$ Various functional groups are compatible with this procedure. However reactions with thioacetals of aliphatic aldehydes were not encouraging.

$$
\mathrm{R}_{\mathrm{R}^{1}}^{\mathrm{RS}} \frac{\mathrm{IBX}}{\mathrm{b} \text {-Cyclodextrin/ } \mathrm{H}_{2} \mathrm{O} / \mathrm{RT}}
$$

The reaction of phenylglyoxal and benzohydrazide in acetonitrile at room temperature generates hydrazide-hydrazone (Scheme 21), When this intermediate is reacted with IBX and tetraethylammonium bromide, $\alpha$-keto-1,3,4oxadiazoles (Table 3, Entry 3 ) are produced. ${ }^{23}$ The reaction was successful with a variety of aryl and heteroaryl glyoxaldehydes, as well as alkyl, aryl and heteroaryl hydrazides. The tetraethylammonium bromide facilitates the polarization of the $\mathrm{I}=0$ bond of IBX to generate a reactive adduct I (Fig. 8). Nucleophilic displacement of bromine from the adduct I by the imine nitrogen of hydrazidehydrazone yields adduct II. Oxidative cyclization and loss of water generates $\alpha$-keto-1,3,4-oxadiazoles.

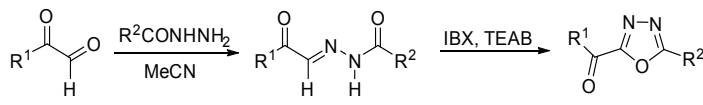

Scheme 21. Formation of $\alpha$-keto-1,3,4-oxadiazoles

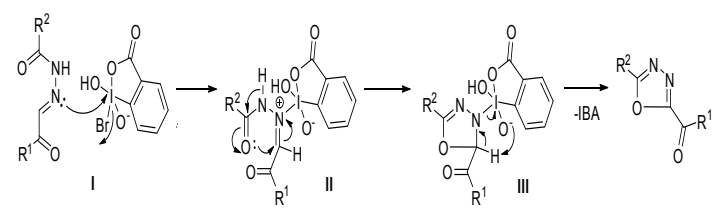

Fig. 8. Conversion of hydrazide-hydrazones to $\alpha$-keto-1,3,4-oxadiazoles

Reaction of o-aminobenzylamine with aldehydes in acetonitrile (Scheme 22) at room temperature using 1.0 or 2.0 equiv. of IBX (Table 3 , Entry 4) afforded dihydroquinazolines and quinazolines, respectively. ${ }^{24}$ The transformation was accomplished with aliphatic, aromatic and heteroaromatic aldehydes. The plausible mechanism involves an attack by the nitrogen $N 1$ of 1,2,3,4tetrahydroquinazoline, formed In situ, on the iodine centre of IBX to afford the intermediate I. This is followed by an elimination reaction to give dihydroquinazoline. A similar attack by N2 on IBX converts dihydroquinazoline into quinazoline. 


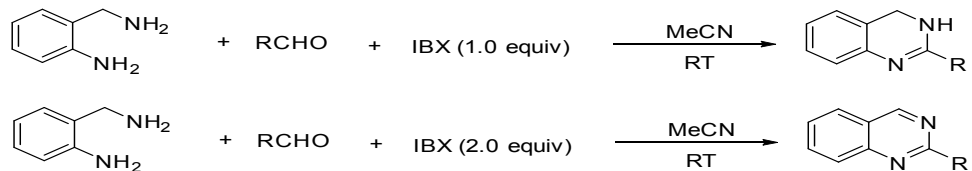

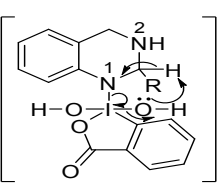

Intermediate I

Scheme 22. Formation of quinazoline derivatives

Table 3: Synthetic reactions mediated by IBX

\begin{tabular}{|c|c|c|c|c|}
\hline Entry & Substrate & Product & Conditions & Yield \\
\hline 1 & & & $\begin{array}{c}\text { IBX ( } 1.0 \text { equiv. }) \\
\text { a } \beta-C D(0.1 \text { equiv. }) \\
\mathrm{H}_{2} \mathrm{O}, \mathrm{RT}\end{array}$ & $92 \%$ \\
\hline 2 & & & $\begin{array}{c}\text { IBX ( } 1.0 \text { equiv. }) \\
\beta-\mathrm{CD}(0.1 \text { equiv. }) \\
\mathrm{H}_{2} \mathrm{O}, \mathrm{RT}\end{array}$ & $90 \%$ \\
\hline 3 & & & $\begin{array}{l}\text { IBX ( } 1.0 \text { equiv. }) \\
\text { TEAB ( } 1.2 \text { equiv. }) \\
\text { MeCN, RT }\end{array}$ & $90 \%$ \\
\hline 4 & & & $\begin{array}{l}\text { IBX (2.0 equiv.), } \\
\text { MeCN, RT }\end{array}$ & $88 \%$ \\
\hline 5 & & & $\begin{array}{l}\text { 1. IBX (4.0 equiv.), } \\
\text { THF:DMSO (10:1), } 90^{\circ} \mathrm{C} \\
\text { 2. }{ }^{\circ} \mathrm{CAN}(5.0 \text { equiv.) } \\
\text { MeCN: } \mathrm{H}_{2} \mathrm{O}(3: 1), 25^{\circ} \mathrm{C}\end{array}$ & $76 \%$ \\
\hline 6 & & & $\begin{array}{c}{ }^{\mathrm{C}} \mathrm{P}-\mathrm{IBX}(1.75 \text { equiv.), } \\
\text { DCM, RT }\end{array}$ & $95 \%$ \\
\hline 7 & & & $\begin{array}{l}\text { IBX ( } 1.0 \text { equiv. }) \\
\beta-\mathrm{CD}(0.1 \text { equiv. }) \\
\mathrm{H}_{2} \mathrm{O}, 60^{\circ} \mathrm{C} \text { to } \mathrm{RT}\end{array}$ & $90 \%$ \\
\hline 8 & $p$-TolsO & & $\begin{array}{c}\text { IBX (2.0 equiv.), } \\
\mathrm{I}_{2}(1.1 \text { equiv. }) \\
\text { MeCN:DMSO ( } 2: 1), \mathrm{RT}\end{array}$ & $76 \%$ \\
\hline 9 & $p$-TolsO ${ }_{2} \mathrm{Na}$ & & $\begin{array}{l}\text { IBX ( } 2.0 \text { equiv.), } \\
\mathrm{I}_{2}(0.25 \text { equiv. }) \\
\text { EtOAc, Reflux }\end{array}$ & $85 \%$ \\
\hline 10 & $\mathrm{Ph}_{\mathrm{Ph}}^{\mathrm{HO}} \underset{\mathrm{Ph}}{\mathrm{OH}}$ & & $\begin{array}{l}\text { IBX ( } 2.0 \text { equiv. }) \\
\text { DMSO, } 80^{\circ} \mathrm{C}\end{array}$ & $90 \%$ \\
\hline
\end{tabular}


2-Cyclohexen-1-ol reacts with p-methoxy phenyl isocyanate in the presence of catalytic amount of DBU to form cyclohexenyl carbamate (Scheme 23). The product on reaction with IBX (Table 3, Entry 5) furnishes bicyclic oxazol-2-one. ${ }^{25}$ The amino group was restored by reaction with cerium(IV) ammonium nitrate.<smiles>COc1ccc(NC(=O)OC2C=CCCC2)cc1</smiles>

Scheme 23. Formation of bicyclic oxazol-2-one

5-Hydroxy-2-iodobenzoic acid coupled to chloromethyl polystyrene cross-linked with $1 \%$ divinylbenzene using $\mathrm{Cs}_{2} \mathrm{CO}_{3}$. It was oxidised to obtain polystyrene supported periodinane reagent (Fig. 9). The reagent converts alcohols to carbonyl compounds (Table 3, Entry 6), in good yields. ${ }^{26} \alpha, \beta-$ Desaturation of carbonyl compounds, and the radical cylization of unsaturated carbamates were also successfully carried out by employing this polymer supported reagent (Scheme 24).

$$
\text { 1. } \mathrm{NaNO}_{2}, \mathrm{KI}
$$

Fig. 9. Preparation of polystyrene supported IBX<smiles>C=CCOC(=O)Nc1ccccc1</smiles>

Scheme 24. Heterocyclization mediated by polymer supported IBX

Epoxides and aziridines were reacted with IBX in presence of $\alpha$-cyclodextrin (Scheme 25) at room temperature to obtain $\beta$-hydroxyketones (Table 3 , Entry 7 ) and $\beta$-aminoketones, respectively. ${ }^{27}$ The reactions do not occur in the absence of cyclodextrin. The cyclodextrin-IBX complex transforms the epoxide to 1,2-diol, and aziridine to amino alcohol, which is thereafter oxidized.

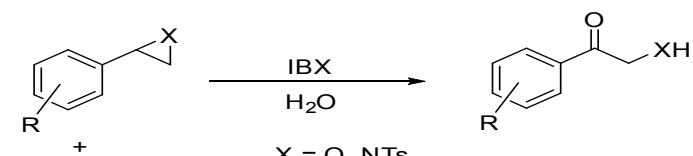

b-cyclodextrin

$X=\mathrm{O}, \mathrm{NTs}$

Scheme 25. Formation of $\beta$-hydroxyketones and $\beta$-aminoketones
Combination of $\mathrm{IBX}-\mathrm{I}^{2}$ facilitates the reactions of alkenes with arenesulfinates (Table 3, Entry 8). This method yields $\alpha$-keto sulfones (Scheme $26)$ in a one-pot reaction. ${ }^{28}$ Acetonitrile-dimethyl sulfoxide (2:1) was used as the medium. The mechanism involves the formation of phenacyl iodide as the intermediate followed by the nucleophilic attack of sulfur atom of arenesulfinate.

$$
\mathrm{R} \curvearrowright \frac{\operatorname{MeCN}-\mathrm{IBM}, \mathrm{I}_{2}}{\mathrm{ArSO}_{2} \mathrm{Na}}
$$

Scheme 26. Formation of $\alpha$-keto sulfones from alkenes

Sodium sulfinates in presence of IBX and catalytic amount of $\mathrm{I}_{2}$ was used for sulfonylation of 1,3-dicarbonyl compounds (Scheme 27), subsequent to deacylation. ${ }^{29}$ The method affords $\beta$-carbonyl sulfones (Table 3, Entry 9) in one step, and in good yields.

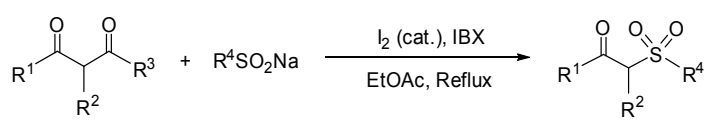

Scheme 27. Formation of $\alpha$-keto sulfones from 1,3-dicarbonyl compounds

IBX oxidizes sec,sec-1,2-diols to the corresponding $\alpha$-ketols without cleaving the glycolic $\mathrm{C}-\mathrm{C}$ bond. However it does not react with tert,tert-1,2-diols, but DMP accomplishes the same transformation. This difference is due to the formation of a 10-I-4 intermediate species with IBX and a 12-I-5 species with DMP. The latter species decomposes rapidly into dicarbonyl compounds, while the former cannot undergo cleavage. The use of a protonating solvent such as TFA with IBX promotes the formation of the 12-I-5 intermediate (Scheme 28). Consequently, with IBX and TFA, all 1,2-diols provide ketones (Table 3 , Entry 10) by oxidative fragmentation. ${ }^{30}$

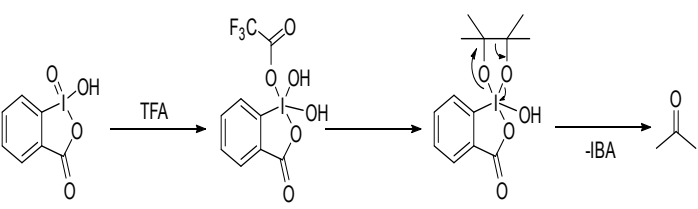

Scheme 28. Oxidative fragmentation of 1,2-diols

IBX in DMSO promotes the oxidative rearrangement of tertiary allylic alcohols. ${ }^{31}$ Thus 1-phenyl-2-cyclohexen-1-ol (Table 4, Entry 1) at room temperature yielded 3-phenyl-2-cyclohexenone (Scheme 29). A rate enhancement was observed with increase in temperature. This indicates that heat is effective for allylic transposition. One of the suggested 
mechanisms (Fig. 10) involves the solvolysis of the tertiary alcohol to an allylic cation (path a). Thereafter an iodic ester is formed at the less substituted terminus that undergoes oxidation. The second mechanism proposes the formation of a tertiary iodic ester (path b) followed by rearrangement and oxidation.<smiles>[R]C1(O)C=CC=CC1</smiles>

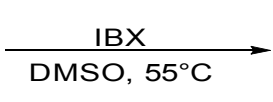<smiles>[R]C1=CC(=O)CCC1</smiles>

Scheme 29. Oxidative rearrangement of tertiary allylic alcohols

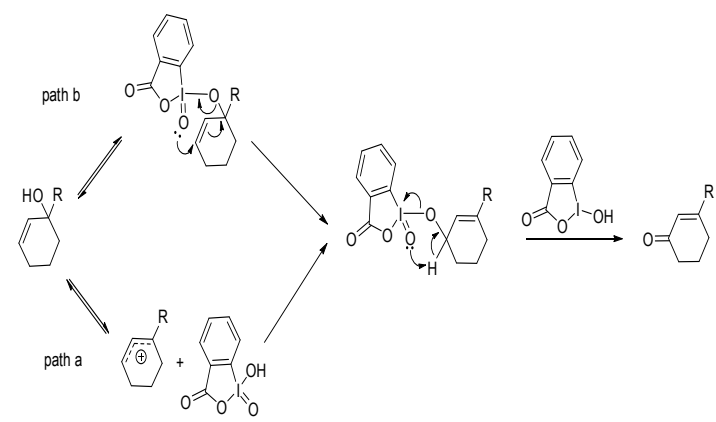

Fig. 10. Oxidative rearrangement of tertiary allylic alcohols Table 4: Substituent modifications promoted by IBX

(IB)

aHexafluoro-2-propanol

The reaction of aldehydes, amines and TMSCN with IBX (Table 4, Entry 2) in the presence of tetrabutylammonium bromide (TBAB) afforded $\alpha$-iminonitriles (Scheme 30 ) in good yields. ${ }^{32}$ The three-component one-pot reaction works well for a wide range of aldehydes and amines.

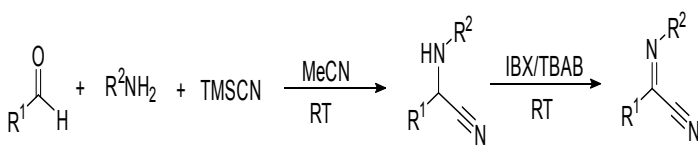

Scheme 30. Formation of $\alpha$-iminonitriles

For the oxidative cleavage of inert $\mathrm{N}$-aryl bonds (Table 4, Entry 3 ) in secondary aromatic amides (Scheme 31) IBX was used in a mixture of hexafluoro-2-propanol (HFIP) and water. ${ }^{33}$ This method demonstrates that an aryl group can be used as a removable protecting group for amides.<smiles>[R]C(=O)Nc1ccccc1</smiles>

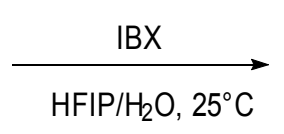<smiles>[R]C(N)=O</smiles>

Scheme 31. Oxidative cleavage of secondary $\mathrm{N}$-aryl amides

Primary carboxamides (Table 4, Entry 4) were transformed to one-carbon dehomologated nitriles (Scheme 32) using IBX and tetraethylammonium bromide. ${ }^{34}$ The mechanism involves the transformation 
of amides to isocyanates and then to imines (Fig. 11). Imines on further oxidation give nitriles.

IBX induces the generation of imines (Table 4, Entry 5) from secondary amines (Scheme 33) under mild conditions. ${ }^{35}$ In DMSO- $\mathrm{H}_{2} \mathrm{O}$ medium, IBX facilitates the cleavage of dithianes also (Scheme 34).

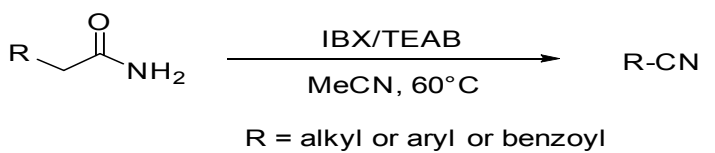

Scheme 32. Formation of dehomologated nitriles

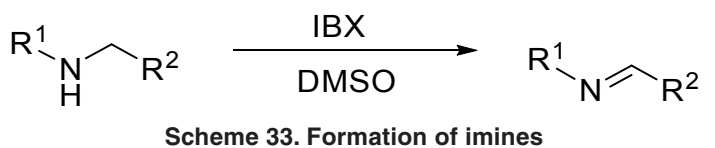

$\alpha, \alpha$-Diphenylacetamide (Table 4, Entry 6) when treated with IBX in presence of TEAB in acetonitrile yielded benzophenone (Scheme 35 ) in excellent yields. ${ }^{36}$ The reaction was optimized with 2.0 equiv. of IBX and 1.0 equiv. of TEAB. Acetamides with aryl and heteroaryl substituents at the $\alpha$-position reacted better than the alkyl counterparts (Figure 12).

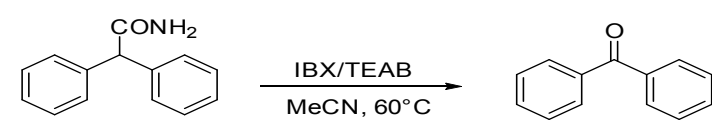
Scheme 35. Conversion of $\alpha, \alpha$-disubstituted acetamides to ketones

$\beta$-Keto esters were converted to tertiary alcohols (Scheme 36) in the presence of IBX (Table 4, Entry 7 ) in a solvent mixture of DMSO and water. ${ }^{37}$ At a temperature of $50^{\circ} \mathrm{C}$, reaction rate was accelerated. Apart from $\beta$-ketoesters, $\beta$-ketoamides and $\beta$-diketones also undergo $\beta$-hydroxylation.

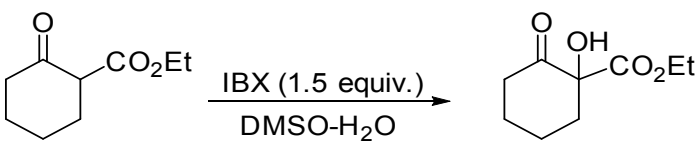

Scheme 36. Conversion of $\beta$-ketoesters to tertiary alcohols

Scheme 34. Cleavage of dithianes

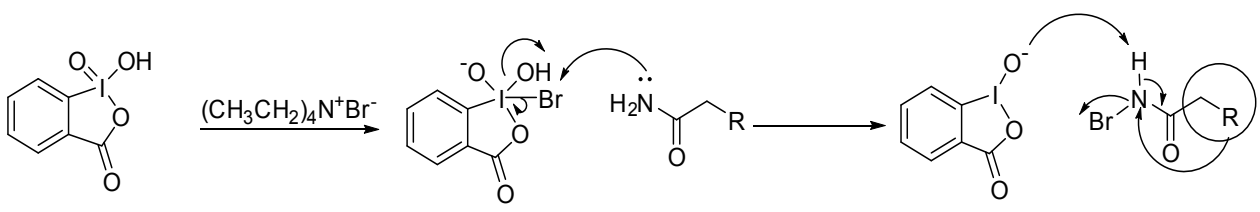

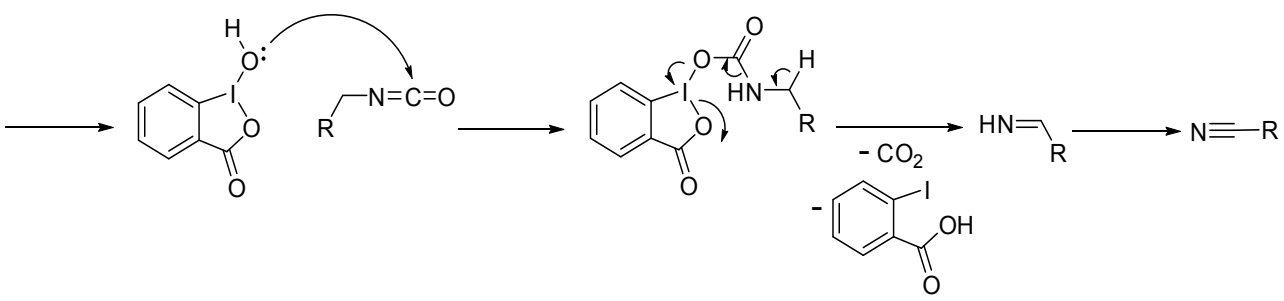

Fig. 11. Conversion of carboxamides to dehomologated nitriles<smiles>[R]C([R])C(N)=O</smiles><smiles></smiles>

Fig. 12. Conversion of $\alpha, \alpha$-disubstituted acetamides to ketones 


\section{CONCLUSION}

Over the last three decades, IBX has become a popular oxidant in organic synthesis. A vast amount of literature is available on the applications of this reagent, especially in the total synthesis of natural products. ${ }^{38}$ IBX enjoys its unique position in chemical space because of its mild nature and simple conditions, transforming a variety of functional groups to desired substituents, with chemoselectivity, and no over-oxidation. The single electron transfer process generates a radical species, which substantiates the reaction mechanisms in many cases. However, detailed investigations need to be carried out to evaluate the scope and potential of this hypervalent iodine reagent. Refinement of the existing methods and demonstration of novel applications would definitely make IBX as one among the widely used oxidants in organic synthesis.

\section{ACKNOWLEDGMENT}

This research did not receive any specific grant from funding agencies in the public, commercial, or not-for-profit sectors.

\section{Conflicts of Interest}

The authors declare no conflict of interest.

\section{REFERENCES}

1. Frigerio, M.; Santagostino, M.; Sputore, S. J. Org. Chem., 1999, 64, 4537-4538.

2. Frigerio, M.; Santagostino, M. Tetrahedron Lett., 1994, 35, 8019-8022.

3. Frigerio, M.; Santagostino, M.; Sputore, S.; Palmisanoj, G. J. Org. Chem., 1995, 60, 7272 7276.

4. Magdziak, D.; Rodriguez, A. A.; Van De Water, R. W., Pettus, T. R. R. Org. Lett., 2002, 4, 285-288.

5. Corey, E. J.; Palani, A. Tetrahedron Lett., 1995, 36, 3485-3488.

6. Thottumkara, A. P.; Vinod, T. K. Tetrahedron Lett., 2002, 43, 569-572.

7. Mülbaier, M. M.; Giannis, A. Angew. Chem. Int. Ed., 2001, 40, 4393-4394.

8. Nicolaou, K. C.; Gray, D. L. F.; Montagnon, T.; Harrison, S. T. Angew. Chem. Int. Ed., 2002, 41, 996-1000.

9. Surendra, K.; Krishnaveni, N. S.; Reddy, M. A.; Nageswar, Y. V. D.; Rao, K. R. J. Org. Chem., 2003, 68, 2058-2059.

10. Nicolaou, K. C.; Baran, P. S.; Zhong, Y-L. J. Am. Chem. Soc., 2001, 123, 3183-3185.

11. More, J. D., Finney, N. S. Org. Lett., 2002, 4, 3001-3003.

12. Kuhakarn, C.; Kittigowittana, K.; Pohmakotr, M.; Reutrakul V. Tetrahedron., 2005, 61, 89959000.

13. Thottumkara, A. P.; Bowsher, M. S.; Vinod T. K. Org. Lett., 2005, 7, 2933-2936.
14. Bartlett, S. L.; Beaudry C. M. J. Org. Chem., 2011, 76, 9852-9855.

15. a) Nicolaou, K. C., Montagnon, T.; Baran, P. S.; Zhong, Y.-L J.Am. Chem. Soc., 2002, 124, 2245 2258; b) Nicolaou, K. C.; Zhong, Y.-L.; Baran, P. S. J. Am. Chem. Soc., 2000, 122, 7596-7597; c) Nicolaou, K. C.; Montagnon, T.; Baran, P. S. Angew. Chem. Int. Ed., 2002, 41, 993-996.

16. Moorthy, J. N.; Senapati, K.; Kumar S. J. Org. Chem., 2009, 74, 6287-6290.

17. Chaudhari, K. H.; Mahajan, U.S.; Bhalerao, D.S. Akamanchi, K. G. Synlett., 2007, 2815-2818.

18. Chaudhari, P. S.; Dangate, P. S.; Akamanchi, K. G. Synlett., 2010, 3065-3067.

19. Deshmukh, S.S.; Chaudhari, K.H.;Akamanchi, K. G. Synlett., 2011, 81-83.

20. Kirsch S. F. J. Org. Chem., 2005, 70, 10210-10212.

21. Krishnaveni, N.S.; Surendra, K.; Nageswar, Y.V. D.; Rao, K. R. Synthesis., 2003, 1968-1970.

22. Krishnaveni, N. S.; Surendra, K.; Nageswar, Y.V. D.; Rao, K. R. Synthesis., 2003, 2295-2297.

23. Kumar, D.; Pilania, M.; Arun, V.; Mishra, B. Synlett., 2014, 25, 1137-1141.

24. Hati, S.; Sen, S. Synthesis., 2016, 48, 1389 1398.

25. Nicolaou, K. C.; Baran, P. S.; Zhong Y-L.; Vega, J. A. Angew. Chem. Int. Ed., 2000, 39, 2525-2529.

26. Sorg, G.; Mengel, A.; Jung, G.; Rademann, J. Angew. Chem. Int. Ed., 2001, 40, 4395-4397. 
27. Surendra, K.; Krishnaveni, N. S.; Reddy, M. A.; Nageswar, Y.V. D.; Rao K. R. J. Org. Chem., 2003, 68, 9119-9121.

28. Samakkanad, N.; Katrun, P.; Techajaroonjit, T.; Hlekhlai, S.; Pohmakotr, M.; Reutrakul, V.; Jaipetch, T.; Soorukram, D.; Kuhakarn, C. Synthesis., 2012, 44, 1693-1699.

29. Katrun, P.; Songsichan, T.; Soorukram, D.; Pohmakotr, M.; Reutrakul, V.; Kuhakarn, C. Synthesis., 2017, 49, 1109-1121.

30. Moorthy, J. N.; Singhal, N.; Senapati, K. Org Biomol. Chem., 2007, 5, 767-771.

31. Shibuya, M.; Ito, S.; Takahashi, M.; Iwabuchi, Y. Org. Lett., 2004, 6, 4303-4306.

32. Fontaine, P.; Chiaroni, A.; Masson, G.;
Zhu, J. Org. Lett., 2008, 10, 1509-1512.

33. Zhang, Z.; Zheng, D.; Wan, Y.; Zhang, G.; Bi, J.; Liu, Q.; Liu, T.; Shi, L. J. Org. Chem., 2018, 83, 1369-1376.

34. Bhalerao, D. S.; Mahajan, U. S.; Chaudhari, K. H.; Akamanchi, K. G. J. Org. Chem., 2007, 72, 662-665.

35. Nicolaou, K. C.; Mathison, C. J. N.; Montagnon T. Angew. Chem. Int. Ed., 2003, 42, 4077-4082.

36. Bellale, E. V.; Bhalerao, D. S.: Akamanchi, K. G. J. Org. Chem., 2008, 73, 9473-9475.

37. Duschek, A.; Kirsch S. F. Chem. Eur. J., 2009, 15, 10713-10717.

38. Duschek, A.; Kirsch, S. F. Angew. Chem. Int. Ed., 2011, 50, 1524-1552. 